\title{
Significance of exosomes in Cardiology: Heralds of cardioprotection
}

\section{Trascendencia de los exosomas en la cardiología: heraldos de la cardioprotección}

Miguel Arroyo-Campuzano* and Cecilia Zazueta

Department of Cardiovascular Biomedicine, Instituto Nacional de Cardiología Ignacio Chávez, Mexico City, Mexico

\begin{abstract}
Exosomes have a key role in intercellular communication. Due to their multiple interactions, these structures fulfill the role of "messengers" in a dynamic way, transporting their content to target-specific cells and generating new cellular signals. This article describes some of the proteins, lipids, and nucleic acids that are transported by these vesicles and that have been related to cardioprotection, to provide information and generate interest in the relevance of exosomes as possible diagnostic and therapeutic targets.
\end{abstract}

Key words: Exosomes. Exosomal cargo. Cardioprotection. Cardioprotective proteins.

\section{Resumen}

Los exosomas tienen un papel clave en la comunicación intercelular. Debido a sus múltiples interacciones, estas estructuras cumplen con el papel de «mensajeros» de forma dinámica, transportando su contenido a células blanco específicas y generando nuevas señales celulares. En este artículo se describen algunas de las proteínas, lípidos y ácidos nucleicos que son transportados por estas vesículas y que se han relacionado con cardioprotección, con la finalidad de proporcionar información y generar interés sobre la relevancia de los exosomas como posibles blancos diagnósticos y terapéuticos.

Palabras clave: Exosomas. Carga exosomal. Cardioprotección. Proteínas cardioprotectoras.

\section{Introduction}

Cells have a complex vesicular traffic system that organizes the transport of both proteins and soluble molecules through the cytoplasm, and molecules that are secreted and that constitute the basis of intercellular communication. In cardiovascular diseases, secretion of these molecules reflects dysregulation in cell homeostasis, as well as cell and tissue dysfunction, but they can also be signals aimed at reducing cell damage ${ }^{1}$.
In this sense, extracellular vesicles (EV), particularly exosomes (EXO), and fulfill a paracrine function, since when released into the extracellular environment they induce antiapoptotic, angiogenic, immunomodulatory, and antifibrotic responses ${ }^{2}$. The cell types described as potential sources of EXO with cardioprotective properties are mesenchymal, cardiac, embryonic, and hematopoietic stem cells ${ }^{3}$. EXOs are lipid nanobodies generated by double membrane endocytosis, which

\section{Correspondence:}

*Miguel Arroyo-Campuzano

E-mail: arroyocampuzanomiguel@gmail.com DOI: 10.24875/ACME.M21000179
Date of reception: 05-07-2020

Date of acceptance: 10-11-2020
Available online: 25-05-2021

Arch Cardiol Mex (Eng). 2021;91(1):95-103
www.archivoscardiologia.com

Arch Cardiol Mex (Eng). 2021;91(1):95-103
www.archivoscardiologia.com license (http://creativecommons.org/licenses/by-nc-nd/4.0/). 
become biocontainers that transfer biomolecules to other cells (proteins, lipids, ribonucleic acid [RNA], and non-coding deoxyribonucleic acid [DNA]), and modifying receptor cells' function ${ }^{2,3}$.

Preclinical trials on cardioprotection using EXO are encouraging; however, generating more information is still required to propose that EXO-mediated effects are directly related to the molecules they carry.

This review describes the findings on the cardioprotective efficacy that different molecules transported by EXOs have, such as caveolins (Cav), heat shock proteins (HSP) and micro RNAs (miRNA, miR), as well as some signaling pathways these molecules participate in. Generating interest in the relevance of the study of EXO in cardioprotection, motivating the development of more preclinical trials, and advancing toward clinical trials is expected.

\section{Exosomes overview}

\section{Exosome characteristics}

EXOs are the smallest EVs, with a size that ranges from 30 to $150 \mathrm{~nm}$ and a density of $1.10-1.14 \mathrm{~g} / \mathrm{mL}^{4}$. They are believed to participate in the removal of membrane proteins; in addition, their presence in different tissues and bodily fluids suggests an important physiological and pathological role in intercellular and/or inter-organ communication ${ }^{5}$. The proteins that are eliminated through this pathway include plasma membrane (PM) proteins, such as transferrin receptor 1 and "lipid rafts" components such as tetraspanins CD9, CD63, and CD81 ${ }^{4}$. These proteins are organized along the membrane in EXO-specific regions and are considered their most common biomarkers ${ }^{6}$. EXOs can have different cellular origin, for example: hematopoietic, epithelial cells, neuroglial cells, and cancer cells $\mathrm{s}^{7}$ therefore, depending on their cellular origin, EXOs usually receive different names, such as cardiosomes, vexosomes, prostasomes, or tolerosomes ${ }^{8}$. EXOs are found in different types of bodily fluids, including blood, saliva, urine, semen, amniotic fluid, breast milk, cerebrospinal fluid, bile, ascites fluid ${ }^{9}$, and pericardial fluid ${ }^{10}$.

\section{Exosomes biogenesis}

Initially, PM must undergo an endocytosis process; by macropinocytosis, dependent on proteins such as clathrin, flotillin, GEEC (glycosylphosphatidylinositol-anchored protein enriched early endosomal compartments), or mediated by caveolae ${ }^{11}$. The internalized compartment is known as early endosome, which matures into late endosome and accumulates intraluminal vesicles (ILV), which is why it is also known as multivesicular endosome (MVE). ILVs are formed by invagination of the MVE membrane, internalizing proteins, nucleic acids, lipids, and cytosol ${ }^{12}$ (Fig. 1).

So far, two main pathways for the formation of ILV have been suggested. The first one is known as endosomal sorting complex required for transport (ESCRT) dependent pathway, which is a complex composed of five multiprotein structures (ESCRT-0, ESCRT-I, ESCRT-II, and ESCRT-III plus the Vps4 complex), which work in coordination to facilitate vesicular budding and cargo selection ${ }^{6}$. At the end of the process, related ESCRT complexes and molecules return to the cytosol, for their reuse ${ }^{13}$.

The second pathway involves neutral sphingomyelinase (nSMase2) ${ }^{14}$, which generates ceramide from sphingomyelin. Ceramide has been shown to induce the binding of microdomains into larger domains, promoting the formation of "buds" on the membrane, and the importance of this pathway lies in that nSMase2 expression downregulation reduces EXO release ${ }^{12}$.

\section{Exosomal content}

Exosomal cargo has common characteristics with other types of EV; however, thanks to various analyses, more specific components have been identified ${ }^{15}$. It has even been determined that this depends of the cell type they are secreted from ${ }^{16}$. Some components of the exosomal structure and content are listed in table 1.

- Proteins: EXOs stand out for containing membrane, cytosolic, and extracellular matrix proteins of approximately 4400 different classes $^{6}$; however, they contain few Golgi complex, endoplasmic reticulum, nucleus, and mitochondrial proteins ${ }^{16}$. The most commonly reported proteins are structural, such as actin, cofilin-1 and tubulin, HSP, integrins, metabolic enzymes, tetraspanins, proteins related to vesicle trafficking such as TSG101 (tumor susceptibility 101) and ALIX protein, surface antigens, immunomodulatory proteins, proteases, and angiogenic molecules, among others ${ }^{28}$.

ESCRT: Endosomal sorting complex required for transport.

- Lipids: regardless of their cellular origin, EXOs are enriched in cholesterol, sphingomyelin and phospholipids, with lipid rafts being formed on their membrane ${ }^{29}$. Lipids are an essential part of the vesicular structure, with up to 280 exosomal lipid species 


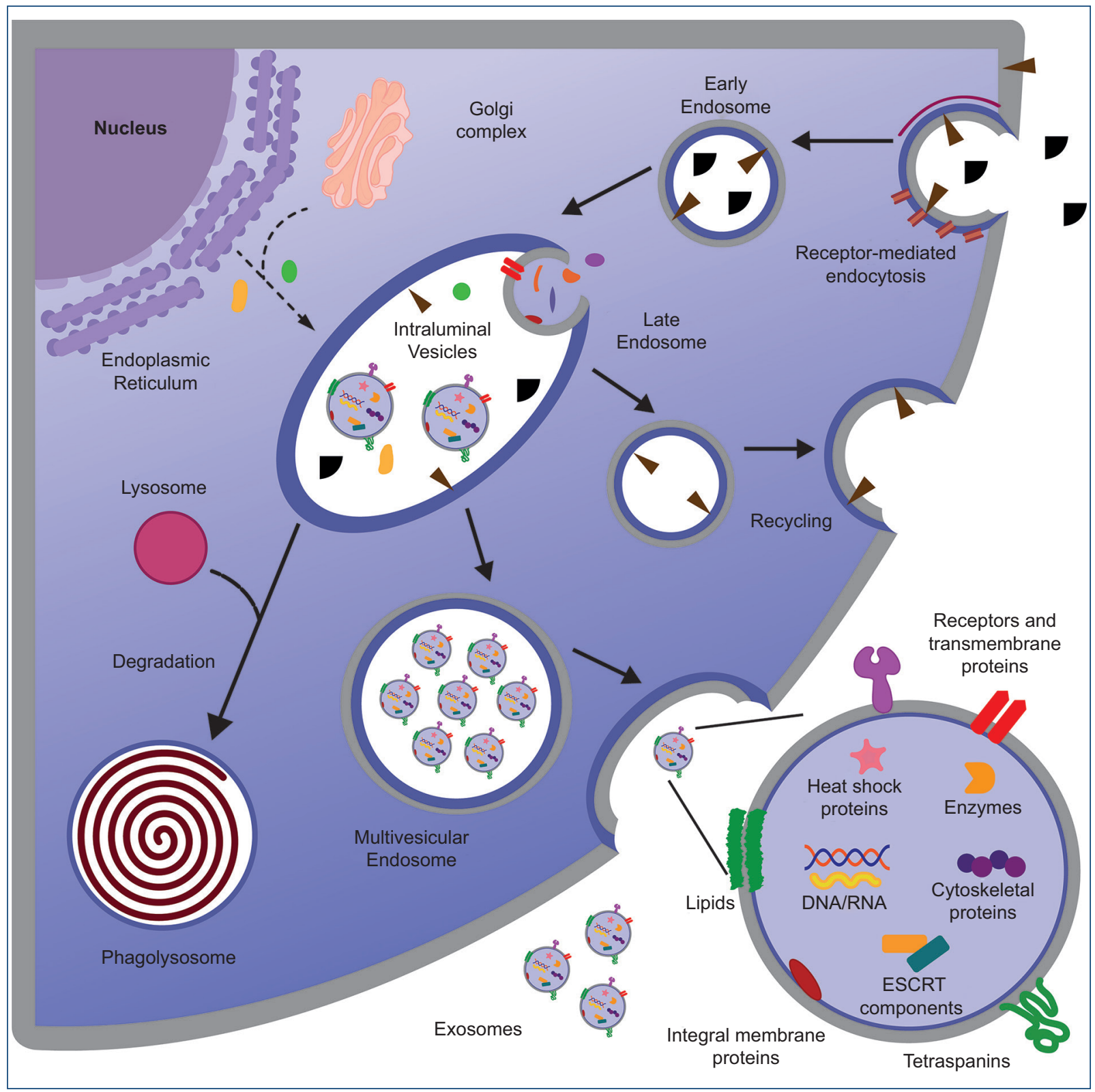

Figure 1. Endomembrane system involved in exosomal biogenesis. Exosomes are generated from dynamic compartmentalization of the plasma membrane (PM), which allows an internalization of macromolecules, surface proteins, ligands, and cellular components and that are subsequently recycled towards the PM, degraded, and/or excreted. The exosomal cargo encompasses different classes of lipids, genetic material, enzymes, and membrane and cytosol proteins.

having been detected ${ }^{30}$. EXOs have greater membrane rigidity compared to $\mathrm{PM}$, since they contain more desaturated phospholipids and due to a high lipid/protein ratio, which is why they are not easily degraded and can circulate freely in biological fluids ${ }^{31}$.

- Nucleic acids: EXOs contain non-coding DNA and RNA; csDNA, cdDNA, mRNA, tRNA, circRNA, MtR$N A$, and pRNA; however, miRNAs or ExomiRs ${ }^{32}$ are the most abundant type of RNA in human plasma $\mathrm{EXOs}^{6}$, even at higher proportions with regard to their cell of origin, due to selectivity mechanisms that operate during the packaging of the cargo ${ }^{33}$. At present, we know that miRNA transport can occur through high-density lipoproteins or by binding to Argonaut 2 and nucleophosmin 1 proteins ${ }^{34}$. Exosomal miRNAs have been reported to be involved in angiogenesis, hematopoiesis, and oncogenesis processes, and 
Table 1. Common exosomal components

\begin{tabular}{|c|c|c|c|c|}
\hline Type & Category & & Examples & Ref. \\
\hline \multirow[t]{14}{*}{ Proteins } & Tetraspanins & \multicolumn{2}{|c|}{ CD9, CD37, CD53, CD55, CD63, CD81, CD82 } & 6,17 \\
\hline & $\begin{array}{l}\text { Cytoskeletal } \\
\text { proteins }\end{array}$ & \multicolumn{2}{|c|}{$\begin{array}{l}\text { Actin, tubulin, cofilin-1, moesin, myosin, vimentin, ezrin, radixin, perlecan, fibronectin, } \\
\text { THBS1, IQGAP1, keratin }\end{array}$} & $6,17,18$ \\
\hline & Biogenesis & \multicolumn{2}{|c|}{ ESCRT-0, I, II, III, Her, Vps4, TSG101, alix, flotillin, clathrin } & 6 \\
\hline & $\begin{array}{l}\text { Transport and } \\
\text { fusion }\end{array}$ & \multicolumn{2}{|c|}{$\begin{array}{l}\text { RAS } 5 \text { and 7-related protein, annexins I, II, IV, V, VI, dynamin, syntaxin-3, RAB4, 5, } 7 \text { and } \\
\text { 11, RAP1B, RABGDI, SLC3A2, CLIC1 }\end{array}$} & $6,17,18$ \\
\hline & $\begin{array}{l}\text { Heat shock } \\
\text { proteins }\end{array}$ & \multicolumn{2}{|c|}{$\begin{array}{l}\alpha \mathrm{B} \text {-crystalline, HSP20, HSP22, HSP27, HSP40, HSP60, HSP70, HSP90, HSC70, HSPA5, } \\
\text { СCT2 }\end{array}$} & $6,18,19,20$ \\
\hline & Adhesion & \multicolumn{2}{|c|}{ ICAM-1, integrins, lactaderin, MFGE8, P-selectin } & 6,17 \\
\hline & $\begin{array}{l}\text { Antigen } \\
\text { presentation }\end{array}$ & \multicolumn{2}{|c|}{ Human leukocyte antigen class I and II } & 6 \\
\hline & $\begin{array}{l}\text { Signaling } \\
\text { proteins }\end{array}$ & \multicolumn{2}{|c|}{$\begin{array}{l}\text { GTPase, HRAS, syntenin-1, Gi2 } \alpha \text {, proteins } 14-3-3, \text { ARF1, CDC42, NRAS, EHD1, EHD4, } \\
\text { RAN, PEBP1, MIF, RRAS2, stomatin, PDCD6 }\end{array}$} & $6,17,18$ \\
\hline & Of transport & \multicolumn{2}{|c|}{ Transferrin receptor } & 6 \\
\hline & Enzymes & \multicolumn{2}{|c|}{$\begin{array}{l}\text { Glucose-6-phosphate isomerase, fatty acid synthase, glyceraldehyde-3-phosphate } \\
\text { dehydrogenase, PFKL, peroxiredoxin-1, hexokinase, phosphoglycerate kinase-1, } \\
\text { phosphoglycerate mutase 1, pyruvate kinase, isoenzymes M1/M2, ATP-citrate lyase, } \\
\text { ATPase, glucose-6-phosphate isomerase, aspartate aminotransferase, aldehyde } \\
\text { reductase, enolase-1, lactate dehydrogenase, aldolase-1, dipeptidyl peptidase-4 }\end{array}$} & $6,17,18,21$ \\
\hline & Cytokines & \multicolumn{2}{|c|}{ Tumor necrosis factor alpha } & 6 \\
\hline & Anti-apoptosis & \multicolumn{2}{|c|}{ Alix, thioredoxin peroxidase } & 17 \\
\hline & $\begin{array}{l}\text { Transcription } \\
\text { regulators }\end{array}$ & \multicolumn{2}{|c|}{ EEF1A1, EEF2, LGALS3, EEF1A2 } & 18 \\
\hline & Caveolae & \multicolumn{2}{|c|}{ Caveoline-1, caveoline-3 } & 22 \\
\hline \multirow[t]{6}{*}{ Lipids } & Phospholipids & \multicolumn{2}{|c|}{ Caveoline- 1 , caveoline- 3} & 23 \\
\hline & Cholesterol & & & 23 \\
\hline & Ceramide & & & 14,23 \\
\hline & Sphingolipids & \multicolumn{2}{|c|}{ Sphingomyelin, hexosylceramide, lactosylceramide } & 17 \\
\hline & Gangliosides & \multicolumn{2}{|c|}{ GM1, GM3 } & 24,25 \\
\hline & Others & \multicolumn{2}{|c|}{$\begin{array}{l}\text { Arachidonic acid, prostaglandin E, 15-d prostaglandin J2, diacylglycerol, triacylglycerol, } \\
\text { hexadecylglycerol }\end{array}$} & 23,26 \\
\hline \multirow[t]{3}{*}{$\begin{array}{l}\text { Nucleic } \\
\text { acids }\end{array}$} & RNA & miRNA & $\begin{array}{l}\text { Let-7, miR-1, miR-15, miR-16, mi-17, mi-R-18, miR-19-19b, } \\
\text { miR-20, miR-21, miR-29a, miR-126, miR-143, miR-145, miR-151, } \\
\text { miR-155, miR-181, miR-200, miR- 214, miR-320, miR-375, miR-382 }\end{array}$ & 6,23 \\
\hline & & \multicolumn{2}{|c|}{ mRNA, circ RNA, mitRNA, tRNA, spRNA, pRNA. } & 6,27 \\
\hline & DNA & \multicolumn{2}{|c|}{ mtDNA, csDNA, cdDNA, viral DNA } & 27 \\
\hline
\end{tabular}

some are only expressed during cardiovascular diseases $^{35}$. The above-mentioned lipid characteristics protect DNA and RNA from degradation mediated by deoxyribonucleases and ribonucleases, present in all bodily fluids ${ }^{32}$

\section{Relevance of exosomes cellular origin and content in cardioprotection}

Exosomal cargo composition has been associated with the specific response of the cell type to different stimuli ${ }^{36}$, with the physiological or pathological state of the donor 


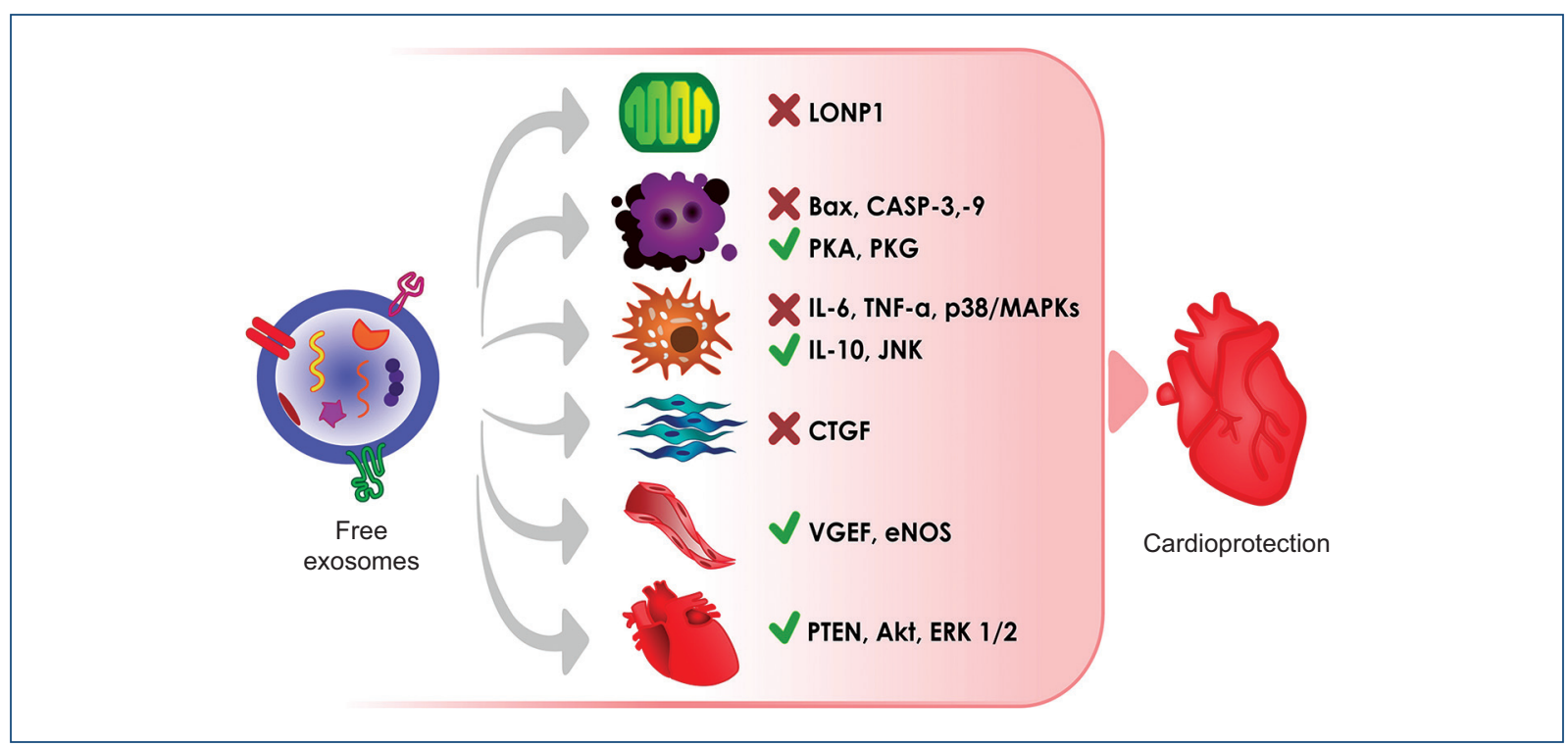

Figure 2. Cardioprotective effects regulated by exosomes. The exosomal content made up of multiple biomolecules triggers a particular message in specific cells and tissues, activating/inhibiting signaling pathways that protect the cardiovascular function. Among these pathways, the following stand out: LONP1 inhibition, which maintains mitochondrial function; caspase inactivation, through Bax, which regulate apoptotic processes; pro-inflammatory cytokines (IL-6 and TNF- $\alpha$ ) and p38/MAPK pathway blockage in immune cells; antifibrotic activity by CTGF inhibition; VGEF and eNOSmediated angiogenesis, and common cardioprotective pathways activation, including PTEN, Akt, and ERK1/2. Akt: protein kinase B; Bax: Bcl-2-associated protein X; CASP 3 and 9: caspases 3 and 9; CTGF: connective tissue growth factor; eNOS: endothelial nitric oxide synthase; ERK1/2: extracellular signal-regulated kinase 1 and 2; IL 6 and 10: interleukins 6 and 10; JNK: c-Jun N-terminal kinases; LONP1: Lon 1 peptidase; MAPK: mitogen activated kinase; PKA: protein kinase A; PKG: protein kinase G; PTEN: phosphatidylinositol-3,4,5-trisphosphate 3-phosphatase; TNF- $\alpha$ : tumor necrosis factor alpha; and VEGF: vascular endothelial growth factor.

cell and with the mechanisms of biogenesis ${ }^{4}$. For example, administration of serum and plasma EXO has been observed to fail to stimulate ERK1/2 (extracellular signal-regulated kinase 1 and 2) protective signaling on cardiomyocytes under hyperglycemia conditions, while under normoglycemia conditions, this kinase is activated by toll-like receptor 4 (TLR4) and HSP2 $27^{37}$. On the other hand, the application of purified plasma EXOs from rats subjected to remote ischemic conditioning decrease infarction size in an ischemia-reperfusion injury (IRI) mod$\mathrm{el}^{38}$. Similarly, EVs obtained from plasma of rats subjected to exercise showed protective effects against IRI ${ }^{39}$. As for the cellular origin of these structures, those originating from pericardial fluid have been reported to improve vascular function, stimulate angiogenesis in in vivo ischemia models, decrease necrosis, and increase vascular density in the affected area ${ }^{10}$. Other studies have demonstrated that mesenchymal stem cell EXOs derived from adipose tissue decrease necrosis and apoptosis in in vivo and in vitro IRI models, after activation of the Wnt/ $\beta v \tau \varepsilon \lambda \sigma, \alpha \phi$ signaling pathway ${ }^{40}$ and that not only EXOs derived from adipose tissue but also those produced by bone marrow and umbilical cord reduce apoptosis and promote angiogenesis after myocardial infarction ${ }^{41}$. Figure 2 illustrates the cardioprotective effect (direct or indirect) of some exosomal structures and proteins.

\section{Caveolae and caveolin}

Caveolae-mediated endocytosis is a pathway for the formation of MVE and, ultimately, EXO. Caveolae are PM invaginations considered as a subtype of "lipid rafts," resulting from interactions between cholesterol, sphingolipids, and sphingomyelin ${ }^{42}$. These 50-100-nm nanodomains are enriched in different cell types, mainly endothelial cells, fibroblasts, adipocytes, and muscle cells ${ }^{43}$. Caveola whole proteins are Cavs: Cav- $1 \alpha$, Cav$1 \beta$, Cav- $2 \alpha$, Cav-2 $\beta$, and Cav- $3^{44}$. Various studies report that caveolae, Cav-1 and Cav-3 are essential for protection against damage by $\mid \mathrm{RI}{ }^{45}$. Caveolae have been proposed to have a mechanoprotective effect and that in the presence of an increase in hemodynamic 
forces (cardiac output), caveolae present in lung endothelium and heart muscle undergo a flattening process, thus increasing the cell surface and releasing tension excess, protecting cells from cell disruption ${ }^{46}$. On the other hand, if caveolae are formed and internalized after membrane closure, they can transport different proteins to intracellular targets, since they possess scaffolding domains for anchoring and regulation of various regulatory and signaling molecules ${ }^{47}$.

Cav-1 is the main structural component of caveola and is predominantly expressed in differentiated cells such as endothelial cells, adipocytes, smooth muscle cells, and type 1 pneumocytes ${ }^{48}$. The importance of Cav-1 in cardioprotection has been demonstrated, given that it attenuates neutrophil-induced cardiac dysfunction ${ }^{49}$ and is overexpressed in pharmacological therapies ${ }^{50}$. On the other hand, Mierke et al. suggest a coordinated interaction of Cav-1 and endothelial nitric oxide synthase in the reduction of vascular intimal layer, in restenosis and in vessel injury in a vascular transplant model ${ }^{51}$. In models of cerebral and limb ischemia, Cav-1 angiogenic effect has been related to vascular endothelial growth factor and its receptor ${ }^{52}$; based on this, it would be interesting to evaluate this relationship in ischemic heart disease.

The presence of Cav-1 mRNA has also been described in serum and plasma of patients with different pathologies, and although the presence of Cav-1 in the extracellular space has been little studied, it is related to hypoxia-induced acute cell damage in some tissues, particularly in the kidney ${ }^{53}$. Cav detachment from PM has been suggested to be the result of hypoxic damage to the caveolar structure. On the other hand, Cav-3 is a protein that is present only in striated muscle cells, where it regulates nitric oxide synthesis, myocyte contraction, and cholesterol metabolism ${ }^{54}$. Feiner et al. demonstrated that Cav-3 levels are reduced in a murine model of left heart failure and in human heart failure ${ }^{55}$. Cav-3 is essential for cardiac protection induced by opioid receptor $\delta$ during preconditioning ${ }^{56}$, while tolerance to IRI is associated with Cav-3 expression ${ }^{57}$. During cardiac stress, autophagy regulates adaptation to cell damage, which seems to depend on Cav-3, managing to preserve mitochondrial function and avoid apoptosis ${ }^{58}$. Conversely, Cav-3 interacts with adiponectin, forming an AdipoR1/Cav-3 complex, which confers cardioprotection by adenine monophosphate-activated kinase $^{59}$. So far, the presence of Cav-3 has not been reported in human plasma EXO.

\section{Heat shock proteins}

HSPs are ubiquitous molecules inducible during cellular stress events, responsible for protein folding, assembly, translocation, and degradation ${ }^{60}$. In EXO and $\mathrm{EV}$, some HSP isoforms have been described to participate in intercellular communication under cardioprotective conditions ${ }^{15}$. For example, HSP20, which is expressed in skeletal, cardiac and smooth muscle, transiently regulates the response to cellular stress ${ }^{61}$. When phosphorylated by protein kinase $\mathrm{A}$ and by protein kinase $G$, it has been shown to inhibit caspase-3 (CASP3) activity, thus decreasing apoptosis ${ }^{62}$. The same authors suggest that its cardioprotective effect in an IRI model is related to a blockade of the $\mathrm{Bax}(\mathrm{Bcl}-2$-associated X protein)/CASP-3 pathway ${ }^{63}$, and its activation can therefore be a key point for protection in ischemic heart disease. It has also been associated with cardiotoxicity reduction in cancer patients treated with doxorubicin ${ }^{64}$.

The HSP60 and HSP70 isoforms are expressed in heart tissue; during hypoxia, these proteins are decoupled from Bax, which allows their translocation to mitochondria, where, by forming pores on the membrane, they favor the release of cytochrome c, which in the cytosol will activate the caspase pathway and death by apoptosis. There is also an HSP60 mitochondrial form, which prevents the degradation of mitochondrial proteins through LONP1 (Lon peptidase 1). The decrease or deletion of mitochondrial HSP60 generates mitochondrial dysfunction and subsequent heart dilatation and failure ${ }^{65}$. HSP60 of exosomal origin binds to TLR4, which promotes the release of tumor necrosis factor alpha (TNF- $\alpha$ ) and interleukin-6 (IL-6) ${ }^{65}$. Extracellular HSP70 has also been reported to likely be helpful to predict survival of patients with heart failure, as increased levels of HSP70 in these patients is associated with higher mortality ${ }^{66}$. Recently, HSP70 overexpression at the vascular level has been documented in models of physical activity, where it prevents endothelial dysfunction and maintains coronary vascular muscles healthy and is able to protect the myocardium against ischemic insult ${ }^{67}$. On the other hand, moderate alcohol consumption has also been associated with post-infarction heart protection, and it is suggested that this effect could be mediated by HSP70, heme oxygenase 1 and manganese superoxide dismutase, the overexpression of which decreases the infarction size and improves ventricular function ${ }^{68}$. These results are correlated with those reported by Guisasola et al., who demonstrate that regular alcohol consumption 
increases the levels of anti-HSP60 antibodies, which stimulates the production of pro-inflammatory cytokines and decreases cardioprotection ${ }^{69}$.

\section{Cytokines}

Immune cells participate in various post-ischemic events: they regulate cellular residues elimination, favor inflammation, and stimulate the formation of scar tissue. Cardiomyocyte EXOs exposed to ischemia have been reported to stimulate bone marrow dendritic cell differentiation. These, in turn, release EXOs that are able to program $\mathrm{CD} 4^{+} \mathrm{T}$ cells, which by secreting chemokines and inflammatory mediators, contribute to improve post-infarction cardiac function ${ }^{70}$. Macrophage-derived miRNAs are also known to promote cardiac inflammation by increasing IL-1 $\beta$ and IL-6, TNF- $\alpha$ and chemokine ligand 2 and, specifically, macrophage-derived EXOs containing miR-155, decrease the proliferation of fibroblasts and increase the inflammatory response, which could damage the repair processes after myocardial infarction ${ }^{71}$. These data emphasize the duality of the inflammatory response and the need for its timely regulation, since, at early infarction phases, this response contributes to improve the survival rate by promoting heart tissue repair, whereas its lack of control leads to cell death and cardiac remodeling failure after an increase in the production of reactive oxygen species, metalloproteinases, and pro-inflammatory cytokines.

The therapeutic potential of these and other EVs is evident, but there are also many not-yet-answered questions regarding the inflammatory response, for example: which are the underlying mechanisms in the packaging and release of cytokines, whether EV-associated forms differ from the free forms in terms of function and whether their allogeneic or autologous application is safe in terms of immunogenicity in patients with cardiovascular diseases.

\section{Exosomal miRNAs}

miRNAs are a class of noncoding RNA that control the expression of some complementary mRNAs. Their presence in serum and plasma suggests that miRNAs can fulfill biological and genetic functions in pathophysiological conditions ${ }^{72}$. In particular, the study of miR-21 and its derivative miR-21-5p in EXOs from mesenchymal stem cells has been shown to have positive paracrine effects on cell survival and angiogenesis, which favors myocardial recovery and vascular regeneration after myocardial infarction ${ }^{73}$. Importantly, miR-21 exerts cardioprotective regulation through the PTEN/Akt (phosphatase and tensin homologue/protein kinase B) signaling pathway ${ }^{73}$. In the same vein, many more miRNAs have been associated with cardiac protection against hypoxic/ischemic events, which is why their study in EXO would provide useful information on cardioprotection mechanisms.

\section{Conclusions}

There is growing evidence that EXOs and other EVs, depending on their cellular origin and changes in their content, have a positive or negative effect in cardiovascular diseases. The study of exosomal biology, and in particular of the molecules transported by these vesicles, will help to define new biomarker candidates for early or late cardiac damage, and to generate new diagnostic, therapeutic, and prognostic options for the management of cardiovascular pathologies. However, since the pathophysiological environment where these vesicles occur can modify their content, further preclinical studies are required in order to know EXOs specific composition and the processes that regulate their biogenesis, cargo selection, secretion, and signaling, in addition to the pathways and cell intercommunication in cardiovascular diseases.

There are novel nanotechnologies whereby, in the near future, microvesicles could be designed in sufficient quantities to reach specific targets, with cargos provided with therapeutic potential for carrying out targeted, and even customized, cardioprotective interventions, as well as to improve and/or produce a synergistic effect with existing cardioprotective therapies.

\section{Funding}

This investigation has not received any specific grant from public, commercial, or non-profit sector agencies.

\section{Conflicts of interest}

None.

\section{Ethical disclosures}

Protection of human and animal subjects. The authors declare that no experiments were performed on humans or animals for this research. 
Confidentiality of data. The authors declare that no patient data appear in this article.

Right to privacy and informed consent. The authors declare that no patient data appear in this article.

\section{References}

1. Hutcheson JD, Aikawa E. Extracellular vesicles in cardiovascular homeostasis and disease. Curr Opin Cardiol. 2018;33(3):290-7.

2. Rezaie J, Rahbarghazi R, Pezeshki M, Mazhar M, Yekani F, Khaksar M et al. Cardioprotective role of extracellular vesicles: A highlight on exosome beneficial effects in cardiovascular diseases. J Cell Physiol. 2019;234(12):21732-45

3. Davidson SM, Yellon DM. Exosomes and cardioprotection - A critical analysis. Mol Aspects Med. 2018r;60:104-14.

4. van Niel G, D'Angelo G, Raposo G. Shedding light on the cell biology of extracellular vesicles. Nat Rev Mol Cell Biol. 2018;19(4):213-28.

5. Théry C, Amigorena S, Raposo G, Clayton A. Isolation and characterization of exosomes from cell culture supernatants and biological fluids. Curr Protoc Cell Biol. 2006; Chapter 3:Unit 3.22.

6. Zhang Y, Liu Y, Liu H, Tang WH. Exosomes: biogenesis, biologic function and clinical potential. Cell Biosci. 2019;9:19.

7. Wolfers J, Lozier A, Raposo G, Regnault A, Théry C, Masurier C, et al. Tumor-derived exosomes are a source of shared tumor rejection antigens for CTL cross-priming. Nat Med. 2001;7(3):297-303.

8. Lee Y, El Andaloussi S, Wood MJ. Exosomes and microvesicles: extracellular vesicles for genetic information transfer and gene therapy. Hum Mol Genet. 2012;21(R1):R125-34.

9. Raposo G, Stoorvogel W. Extracellular vesicles: exosomes, microvesicles, and friends. J Cell Biol. 2013;200(4):373-83.

10. Beltrami C, Besnier M, Shantikumar S, Shearn Al, Rajakaruna C, Laftah A, et al. Human pericardial fluid contains exosomes enriched with cardiovascular-expressed microRNAs and promotes therapeutic angiogenesis. Mol Ther. 2017;25(3):679-93.

11. Miaczynska M, Stenmark $\mathrm{H}$. Mechanisms and functions of endocytosis. J Cell Biol. 2008;180(1):7-11.

12. Hessvik NP, Llorente A. Current knowledge on exosome biogenesis and release. Cell Mol Life Sci. 2018;75(2):193-208.

13. Elkin SR, Lakoduk AM, Schmid SL. Endocytic pathways and endosomal trafficking: a primer. Wien Med Wochenschr. 2016;166(7-8):196-204.

14. Elsherbini A, Bieberich E. Ceramide and exosomes: A novel target in cancer biology and therapy. Adv Cancer Res. 2018;140:121-54.

15. Kowal J, Arras G, Colombo M, Jouve M, Morath JP, Primdal-Bengtson B, etal Proteomic comparison defines novel markers to characterize heterogeneous populations of extracellular vesicle subtypes. Proc Natl Acad Sci U S A. 2016;113(8):E968-77.

16. Haraszti RA, Didiot MC, Sapp E, Leszyk J, Shaffer SA, Rockwell HE, et al. High-resolution proteomic and lipidomic analysis of exosomes and microvesicles from different cell sources. J Extracell Vesicles. 2016;5:32570.

17. Théry C, Zitvogel L, Amigorena S. Exosomes: composition, biogenesis and function. Nat Rev Immunol. 2002;2(8):569-79.

18. Mathivanan S, Ji H, Simpson RJ. Exosomes: extracellular organelles important in intercellular communication. J Proteomics. 2010;73(10):1907-20

19. Reddy VS, Madala SK, Trinath J, Reddy GB. Extracellular small heat shock proteins: exosomal biogenesis and function. Cell Stress Chaperones. 2018;23(3):441-54.

20. Wyciszkiewicz A, Kalinowska-Łyszczarz A, Nowakowski B, Kaźmierczak K, Osztynowicz K, Michalak S. Expression of small heat shock proteins in exosomes from patients with gynecologic cancers. Sci Rep. 2019;9(1):9817.

21. Göran Ronquist K. Extracellular vesicles and energy metabolism. Clin Chim Acta. 2019; 488:116-21.

22. Logozzi M, De Milito A, Lugini L, Borghi M, Calabrò L, Spada M, et al. High levels of exosomes expressing CD63 and caveolin-1 in plasma of melanoma patients. PLoS One. 2009;4(4):e5219.

23. Record M, Subra C, Silvente-Poirot S, Poirot M. Exosomes as intercellular signalosomes and pharmacological effectors. Biochem Pharmacol. 2011;81(10):1171-82.

24. Parolini I, Federici C, Raggi C, Lugini L, Palleschi S, De Milito A, et al. Microenvironmental $\mathrm{pH}$ is a key factor for exosome traffic in tumor cells. J Biol Chem. 2009;284(49):34211-22.

25. Yuyama K, Yamamoto N, Yanagisawa K. Accelerated release of exosome-associated GM1 ganglioside (GM1) by endocytic pathway abnormality: another putative pathway for GM1-induced amyloid fibril formation. J Neurochem. 2008;105(1):217-24
26. Subra C, Grand D, Laulagnier K, Stella A, Lambeau G, Paillasse M, et al. Exosomes account for vesicle-mediated transcellular transport of activatable phospholipases and prostaglandins. J Lipid Res. 2010;51(8):2105-20.

27. Kalluri R, LeBleu VS. Discovery of double-stranded genomic DNA in circulating exosomes. Cold Spring Harb Symp Quant Biol. 2016;81: 275-80.

28. Choi DS, Kim DK, Kim YK, Gho YS. Proteomics of extracellular vesicles: Exosomes and ectosomes. Mass Spectrom Rev. 2015;34(4):474-90.

29. Llorente A, Skotland T, Sylvänne T, Kauhanen D, Róg T, Orłowski A, et al. Molecular lipidomics of exosomes released by PC-3 prostate cancer cells. Biochim Biophys Acta. 2013;1831(7):1302-9.

30. Skotland T, Sandvig K, Llorente A. Lipids in exosomes: Current knowledge and the way forward. Prog Lipid Res. 2017;66:30-41.

31. Record M, Silvente-Poirot S, Poirot M, Wakelam MJO. Extracellular vesicles: lipids as key components of their biogenesis and functions. J Lipid Res. 2018;59(8):1316-24.

32. Bhome R, Del Vecchio F, Lee GH, Bullock MD, Primrose JN, Sayan AE, et al. Exosomal microRNAs (exomiRs): Small molecules with a big role in cancer. Version 2. Cancer Lett. 2018;420:228-35.

33. Guduric-Fuchs J, O'Connor A, Camp B, O'Neill CL, Medina RJ, Simpson DA. Selective extracellular vesicle-mediated export of an overlapping set of microRNAs from multiple cell types. BMC Genomics. 2012;13:357.

34. Zhang J, Li S, Li L, Li M, Guo C, Yao J, et al. Exosome and exosomal microRNA: trafficking, sorting, and function. Genomics Proteomics Bioinformatics. 2015;13(1):17-24.

35. Khalyfa A, Gozal D. Exosomal miRNAs as potential biomarkers of cardiovascular risk in children. J Transl Med. 2014;12:162.

36. Villarroya-Beltri $\mathrm{C}$, Baixauli $\mathrm{F}$, Mittelbrunn M, Fernández-Delgado I, Torralba D, Moreno-Gonzalo O, et al. ISGylation controls exosome secretion by promoting lysosomal degradation of MVB proteins. Nat Commun. 2016;7:13588.

37. Gartz M, Strande JL. Examining the paracrine effects of exosomes in cardiovascular disease and repair. J Am Heart Assoc. 2018;7(11):e007954.

38. Vicencio JM, Yellon DM, Sivaraman V, Das D, Boi-Doku C, et al. Plasma exosomes protect the myocardium from ischemia-reperfusion injury. $J$ Am Coll Cardiol. 2015;65(15):1525-36.

39. Bei Y, Xu T, Lv D, Yu P, Xu J, Che L, et al. Exercise-induced circulating extracellular vesicles protect against cardiac ischemia-reperfusion injury. Basic Res Cardiol. 2017;112(4):38.

40. Cui X, He Z, Liang Z, Chen Z, Wang H, Zhang J. Exosomes from adipose-derived mesenchymal stem cells protect the myocardium against ischemia/reperfusion injury through Wnt/ $\beta$-catenin signaling pathway. $J$ Cardiovasc Pharmacol. 2017;70(4):225-31.

41. Xu H, Wang Z, Liu L, Zhang B, Li B. Exosomes derived from adipose tissue, bone marrow, and umbilical cord blood for cardioprotection after myocardial infarction. J Cell Biochem. 2020;121(3):2089-102.

42. Shaul PW, Anderson RG. Role of plasmalemmal caveolae in signal transduction. Am J Physiol. 1998;275(5):L843-51.

43. Kruglikov IL, Scherer PE. Caveolin-1 as a pathophysiological factor and target in psoriasis. NPJ Aging Mech Dis. 2019;5:4.

44. Schwencke C, Braun-Dullaeus RC, Wunderlich C, Strasser RH. Caveolae and caveolin in transmembrane signaling: Implications for human disease. Cardiovasc Res. 2006;70(1):42-9.

45. Fridolfsson HN, Kawaraguchi Y, Ali SS, Panneerselvam M, Niesman IR, Finley JC, et al. Mitochondria-localized caveolin in adaptation to cellular stress and injury. FASEB J. 2012;26(11):4637-49.

46. Cheng JP, Mendoza-Topaz C, Howard G, Chadwick J, Shvets E, Cowburn AS, et al. Caveolae protect endothelial cells from membrane rupture during increased cardiac output. J Cell Biol. 2015;211(1):53-61.

47. Patel HH, Head BP, Petersen HN, Niesman IR, Huang D, Gross GJ, et al. Protection of adult rat cardiac myocytes from ischemic cell death: role of caveolar microdomains and delta-opioid receptors. Am J Physiol Heart Circ Physiol. 2006;291(1):H344-50.

48. Sanon VP, Sawaki D, Mjaatvedt CH, Jourdan-Le Saux C. Myocardial tissue caveolae. Compr Physiol. 2015;5(2):871-86.

49. Young LH, Ikeda Y, Lefer AM. Caveolin-1 peptide exerts cardioprotective effects in myocardial ischemia-reperfusion via nitric oxide mechanism. Am J Physiol Heart Circ Physiol. 2001;280(6):H2489-95.

50. Patel HH, Tsutsumi YM, Head BP, Niesman IR, Jennings M, Horikawa $Y$, et al. Mechanisms of cardiac protection from ischemia/reperfusion injury: a role for caveolae and caveolin-1. FASEB J. 2007;21(7):1565-74.

51. Mierke J, Christoph M, Pfluecke C, Jellinghaus S, Wunderlich C, Strasser $\mathrm{RH}$, et al. Atheroprotective role of caveolin-1 and eNOS in an innovative transplantation model is mainly mediated by local effects. Biochim Biophys Acta Mol Basis Dis. 2017;1863(2):529-36.

52. Gao $Y$, Zhao $Y$, Pan J, Yang L, Huang T, Feng $X$, et al. Treadmill exercise promotes angiogenesis in the ischemic penumbra of rat brains through caveolin-1/VEGF signaling pathways. Brain Res. 2014;1585:83-90.

53. Zager RA, Johnson A, Hanson S, de la Rosa V. Altered cholesterol localization and caveolin expression during the evolution of acute renal failure. Kidney Int. 2002;61(5):1674-83.

54. Sanon VP, Sawaki D, Mjaatvedt CH, Jourdan-Le Saux C. Myocardial tissue caveolae. Compr Physiol. 2015;5(2):871-86. 
55. Feiner EC, Chung $P$, Jasmin JF, Zhang J, Whitaker-Menezes $D$ Myers $\mathrm{V}$, et al. Left ventricular dysfunction in murine models of heart failure and in failing human heart is associated with a selective decrease in the expression of caveolin-3. J Card Fail. 2011;17(3):253-63.

56. Tsutsumi YM, Kawaraguchi Y, Niesman IR, Patel HH, Roth DM. Opioid-induced preconditioning is dependent on caveolin-3 expression. Anesth Analg. 2010;111(5):1117-21.

57. See Hoe LE, Schilling JM, Tarbit E, Kiessling CJ, Busija AR, Niesman IR, et al. Sarcolemmal cholesterol and caveolin-3 dependence of cardiac function, ischemic tolerance, and opioidergic cardioprotection. Am J Physiol Heart Circ Physiol. 2014;307(6):H895-903.

58. Kassan A, Pham U, Nguyen Q, Reichelt ME, Cho E, Patel PM, et al Caveolin-3 plays a critical role in autophagy after ischemia-reperfusion. Am J Physiol Cell Physiol. 2016:311(6):C854-65.

59. Wang $Y$, Wang $X$, Jasmin JF, Lau WB, Li R, Yuan $Y$, et al. Essential role of caveolin-3 in adiponectin signalsome formation and adiponectin cardioprotection. Arterioscler Thromb Vasc Biol. 2012;32(4):934-42.

60. Park CJ, Seo YS. Heat shock proteins: A review of the molecular chaperones for plant immunity. Plant Pathol J. 2015;31(4):323-33.

61. Martin TP, Currie S, Baillie GS. The cardioprotective role of small heatshock protein 20. Biochem Soc Trans. 2014;42(2):270-73.

62. Fan GC, Chu G, Mitton B, Song Q, Yuan Q, Kranias EG. Small heatshock protein Hsp20 phosphorylation inhibits beta-agonist-induced cardiac apoptosis. Circ Res. 2004;94(11):1474-82.

63. Fan GC, Ren X, Qian J, Yuan Q, Nicolaou $P$, Wang $Y$, et al. Novel cardioprotective role of a small heat-shock protein, Hsp20, against ische$\mathrm{mia} /$ reperfusion injury. Circulation. 2005;111(14):1792-9.

64. Fan GC, Zhou X, Wang X, Song G, Qian J, Nicolaou P, et al. Heat shock protein 20 interacting with phosphorylated Akt reduces doxorubicin-triggered oxidative stress and cardiotoxicity. Circ Res. 2008;103(11):1270-9.
65. Duan Y, Tang H, Mitchell-Silbaugh K, Fang X, Han Z, Ouyang K. Heat shock protein 60 in cardiovascular physiology and diseases. Front Mol Biosci. 2020;7:73.

66. Jenei ZM, Gombos T, Förhécz Z Pozsonyi Z, Karádi I, Jánoskuti L, et al. Elevated extracellular HSP70 (HSPA1A) level as an independent prognostic marker of mortality in patients with heart failure. Cell Stress Chaperones. 2013:18(6):809-13.

67. Milne KJ, Wolff S, Noble EG. Myocardial accumulation and localization of the inducible $70-\mathrm{kDa}$ heat shock protein, Hsp70, following exercise. J Appl Physiol (1985). 2012;113(6):853-60.

68. Sato M, Fraga C, Das DK. Induction of the expression of cardioprotective proteins after mild-to-moderate consumption of alcohol. Pathophysiology. 2004;10(2):139-45.

69. Guisasola MC. Role of heat shock proteins in the cardioprotection of regular moderate alcohol consumption. Med Clin (Barc). 2016;146(7):292-300.

70. Liu H, Gao W, Yuan J, Wu C, Yao K, Zhang L, at al. Exosomes derived from dendritic cells improve cardiac function via activation of CD4(+) T lymphocytes after myocardial infarction. J Mol Cell Cardiol. 2016;91: 123-33.

71. Wang C, Zhang C, Liu L, A X, Chen B, Li Y, et al. Macrophage-derived mir-155-containing exosomes suppress fibroblast proliferation and promote fibroblast inflammation during cardiac injury. Mol Ther. 2017;25(1):192-204.

72. Vaka VR, McMaster KM, Cornelius DC, Ibrahim T, Jayaram A, Usry N et al. Natural killer cells contribute to mitochondrial dysfunction in response to placental ischemia in reduced uterine perfusion pressure rats. Am J Physiol Regul Integr Comp Physiol. 2019;316(5):R441-7.

73. Wang $\mathrm{K}$, Jiang Z, Webster KA, Chen J, Hu H, Zhou Y, et al. Enhanced cardioprotection by human endometrium mesenchymal stem cells driven by exosomal microRNA-21. Stem Cells Transl Med. 2017;6(1):209-22. 